\title{
Implementación de un protocolo para la producción de raíces pilosas (hairy roots) de uña de gato (Uncaria tomentosa) mediante transformación con Agrobacterium rhizogenes
}

\author{
Implementation of a protocol for the production \\ of hairy roots of cat's claw (Uncaria tomentosa) by \\ Agrobacterium rhizogenes mediated transformation
}

Giovanni Garro Monge'

Karina Ramijan Carmiol

Bárbara Blanco Ulate 3

Kalai Lam Cheng ${ }^{4}$

Silvana Alvarenga Venutolo

Fecha de recepción: 29 de setiembre del 2011

Fecha de aprobación: 3 de febrero del 2012

Garro, G; Ramijan, K; Blanco, B; Lam, K; Alvarenga, S. Implementación de un protocolo para la producción de raíces pilosas (hairy roots) de uña de gato (Uncaria tomentosa) mediante transformación con Agrobacterium rhizogenes. Tecnología en Marcha. Vol. 25, No 3. Julio-Setiembre 20 I2. Pág 28-38.

Biólogo, Escuela de Biología, Tecnológico de Costa Rica. Teléfono: 2550-9162. Correo electrónico: ggarro@itcr.ac.cr

2 Ingeniera en Biotecnología. Estudiante de posgrado, Universidad Tecnológica de Hamburgo (TUHH). Correo electrónico: karinaramijan@yahoo.com

3 Ingeniera en Biotecnología, Estudiante de Doctorado, University of California, Davis. Correo electrónico: bblanco@ucdavis.edu

4 Ingeniera en Biotecnología. Estudiante de Maestría, University of California, Davis. Teléfono: 2219-5555 Correo electrónico: I.kalai@gmail.com

5 Bióloga, Escuela de Biología, Tecnológico de Costa Rica. Teléfono: 2550-2479. Correo electrónico: salvarenga@itcr.ac.cr 


\section{Resumen}

Los beneficios para la salud registrados a partir del uso de metabolitos secundarios de la planta llamada uña de gato (Uncaria tomentosa) han generado una fuerte demanda comercial, así como la extracción intensiva de esta especie en los países en los cuales se distribuye, con el consecuente deterioro de este recurso genético en su hábitat natural.

Es por eso que resulta necesario implementar protocolos de cultivo de células y tejidos de esta especie, con el fin de lograr la síntesis de los compuestos en forma controlada. La corteza de las raíces es uno de los tejidos en los que se concentra la producción de estos compuestos, razón por la cual la producción de raíces de cabellera (hairy roots) resulta ser una técnica alternativa para la producción a escala de los metabolitos de interés.

En este proyecto se implementó un protocolo de agroinfección de microestacas de $U$. tomentosa utilizando cepas silvestres de Agrobacterium rizhogenes (ARI500 y A4RS), así como el mantenimiento en medio líquido de las raíces pilosas obtenidas. En colaboración con el Laboratorio de Biología Molecular del programa PIPRA (UC Davis), se determinó la eficacia del protocolo de agroinfección, así como el uso de otras herramientas moleculares para la detección de expresión génica, las cuales mostraron resultados satisfactorios en los ensayos de agroinfección, bajo las metodologías establecidas en el proyecto.

\section{Palabras clave}

Agrobacterium rhizogenes, agroinfección, Uncaria tomentosa, raíces pilosas.

\begin{abstract}
The beneficial health properties registered of secondary metabolites produced by the plant cat's claw (Uncaria tomentosa) had generated a strong market demand and intensive extraction of this species in the countries where distributed, with the deterioration of this genetic resource in its natural habitat.
\end{abstract}

Because of this, is necessary to implement protocols for cell and tissue culture of this species in order to achieve the synthesis of compounds in a controlled manner. The root bark is one of the tissues where the production of these compounds is concentrated. Because of this, the production of hairy roots becomes an alternative technique for scale production of the metabolites of interest.

In this research, a protocol was implemented using agroinfection of $U$. tomentosa shoot tips with wild strains of Agrobacterium rizhogenes (ARI500 and A4RS) and maintenance of hairy roots obtained. In collaboration with the Laboratory of Molecular Biology of the PIPRA program (UC Davis), we determined the efficacy of this agroinfection protocol and the use of other molecular tools which showed satisfactory results in testing agroinfection under the methodologies established.

\section{Key words}

Agrobacterium rhizogenes, agroinfection, Uncaria tomentosa, hairy roots. 


\section{Introducción}

La planta Uncaria tomentosa (uña de gato) es una liana espinosa muy popular por sus propiedades curativas, ya que posee actividades antibacterianas, antivirales, anticancerígenas, antioxidantes, antiinflamatorias e inmunoestimulantes. Actualmente se recomienda para múltiples usos terapéuticos, como por ejemplo, tratamiento de abscesos, alergias, artritis, asma, cáncer, efectos secundarios de la quimioterapia, prevención de enfermedades, fiebre, úlcera gástrica, hemorragias, inflamación, irregularidades menstruales, reumatismo, afecciones dérmicas, inflamación del tracto urinario, infecciones víricas y heridas (Keplinger et al., 1998, Pereira et al., 2008, Pero, 200 I, Bobrowski, 2004).

En los últimos años se ha presentado una fuerte demanda comercial de productos elaborados a partir de uña de gato y en más de 30 países se comercializan los derivados de esta planta. No obstante, a nivel mundial el procesamiento de los compuestos medicinales de $U$. tomentosa es muy limitado, concentrándose en un grupo de industrias situadas en Sudamérica, Estados Unidos y Canadá (Falkiewicz et al., 200I). En Costa Rica existe poca explotación comercial de esta planta como materia prima para la producción de pastillas y pildoras elaboradas a partir de este recurso natural (Alvarenga et al., 2008, Alvarenga, 20 I0).

Las propiedades medicinales de esta planta se atribuyen a los metabolitos secundarios (alcaloides) presentes principalmente en la raíz y la corteza. Por eso se ha propuesto el empleo del cultivo de raíces para la obtención de estos compuestos. Sin embargo, el cultivo de las raíces de forma convencional presenta ciertas limitaciones, entre las cuales se pueden mencionar: la velocidad de producción de biomasa es lenta y requiere de auxinas (hormona vegetal) para su crecimiento, lo cual provoca una disminución en el contenido de alcaloides, baja estabilidad para mantenerse en cultivo y baja estabilidad en la producción de metabolitos secundarios (Heitzman et al., 2005).

Una estrategia novedosa para abordar esta problemática es el empleo de un cultivo de raíces de cabellera obtenidas por transformación con la bacteria Agrobacterium rhizogenes. Se considera que este tipo de cultivo es un valioso sistema de producción de metabolitos secundarios, porque no requiere de reguladores de crecimiento y posee tasas de crecimiento estables y rápidas, compatibles con suspensiones celulares; además, presenta estabilidad genética y bioquímica y favorece la producción de algunos compuestos secundarios en comparación con cultivos convencionales (Náder et al., 2004).

La fuerte demanda comercial de esta especie podría incrementar las tasas de extracción del recurso en los países en los cuales se distribuye en forma natural, con el consecuente deterioro de este recurso genético en su hábitat. Por lo tanto, es necesario implementar protocolos de micropropagación y cultivo de raíces de U. tomentosa como instrumento básico para su utilización y posible explotación comercial como fuente de metabolitos secundarios.

Al respecto, en los últimos años, en el Programa de Plantas Medicinales del Centro de Investigación en Biotecnología (CIB) del Tecnológico de Costa Rica (TEC) se han realizado investigaciones con el fin de establecer metodologías eficaces de micropropagación de uña de gato y metodologías para la identificación, producción y extracción de alcaloides de esta planta medicinal.

El objetivo general de este proyecto es la producción in vitro de raíces en cabellera de $U$. tomentosa mediante la transformación con A. rhizogenes para la obtención de metabolitos secundarios de interés farmacológico.

\section{Materiales y métodos}

Obtención de plántulas viables de $U$. tomentosa a nivel de invernadero para la extracción de brotes

Se recolectaron plantas de $U$. tomentosa de la región atlántica del país, específicamente de las localidades de Las Colinas y la Roxana de Guápiles. Estas se colocaron en una cámara húmeda en el invernadero del Centro de Investigación en Biotecnología (CIB) del Tecnológico de Costa Rica (TEC) y se les dio un tratamiento mensual con soluciones de BAP, Agrimycin ${ }^{\circledR}$ y Benomil@. Asimismo, se les aplicó una fertilización foliar con Bayfolan Forte ${ }^{\circledR}$ una vez al mes. 
Establecimiento in vitro de microestacas y micropropagación de U. tomentosa

Primeramente se recolectaron brotes axilares con una morfología adecuada de las plantas de $U$. tomentosa que se encontraban en el invernadero de investigación del CIB. Se procedió a lavarlos con agua y jabón quirúrgico empleando un cepillo. Luego se sumergieron en una solución de Agrimycin ${ }^{\circledR}$, Benomil $®$ y Ferbán durante 1.5 horas en agitación. Después se introdujeron en una solución de $\mathrm{HgCl}_{2}$ al 0,1\% durante 26 minutos en agitación. Se transfirieron a la cámara de flujo laminar, donde se lavaron con agua destilada estéril. Por último, se inocularon los explantes en un medio de cultivo MS (1962) complementado con 3mg/L de BAP (Alvarenga, 2010).

Para llevar a cabo la micropropagación, se aislaron microestacas y se inocularon en un medio de cultivo MS (1962) complementado con 3mg/L de BAP. Las microestacas se incubaron a una temperatura de $25-27^{\circ} \mathrm{C}$, un fotoperiodo de 16 horas luz (Alvarenga,20 I0).

Preparación de un cultivo de $\mathrm{A}$. rhizogenes competente para transformación a partir de las cepas A4PC, A4RS y ARI 500

Las cepas A4PC, A4RS y ARI500 de A. rhizogenes empleadas en este proyecto fueron proporcionadas por el Dr. Edmundo Lozoya, investigador del Departamento de Ingeniería Genética, CINVESTAVIPN, Unidad Irapuato.
Para el establecimiento de un cultivo bacteriano fresco de cada cepa, se procedió a seguir una metodología estandarizada según Peña (2005) y Wang (2006). Se inocularon $5 \mathrm{~mL}$ de un cultivo de 48 horas en $50 \mathrm{~mL}$ de medio LB líquido suplementado con $50 \mathrm{mg} / \mathrm{L}$ de Rifampicina, y el subcultivo se incubó durante 48 horas a $28{ }^{\circ} \mathrm{C}$ en agitación. La densidad óptica de los cultivos bacterianos se determinó empleando un espectrofotómetro a $600 \mathrm{~nm}$ de longitud de onda .

Para almacenar las cepas A4PC, A4RS y ARI500, se procedió a centrifugar el cultivo bacteriano establecido en medio selectivo con anterioridad a 2700 rpm por 20 minutos. Luego, se resuspendió el pellet bacteriano en buffer TE estéril. Por último, se almacenaron las cepas en glicerol al $10 \%$ y a $-20{ }^{\circ} \mathrm{C}$ hasta su próximo uso (Wang 2006).

Pruebas de susceptibilidad a diferentes concentraciones de los antibióticos Rifampicina y Cefotaxime en microestacas de U. tomentosa

Se prepararon diferentes tratamientos, según se muestra en el cuadro I, tomando como base el medio de cultivo MS (1962) complementado con $3 \mathrm{mg} / \mathrm{L}$ de BAP.

En el montaje de los ensayos de susceptibilidad a antibióticos se inocularon dos microestacas por frasco y se utilizaron 15 frascos en cada tratamiento $(n=30)$ con medio de cultivo a una temperatura de $25-27^{\circ} \mathrm{C}$, un fotoperiodo de 16 horas luz y las evaluaciones se llevaron a cabo semanalmente durante un periodo de tres semanas.

Cuadro I.Tratamientos para los ensayos de susceptibilidad a los antibióticos Rifampicina (R-I, $\mathrm{R}-2$ y R-3) y Cefotaxime (C-I, C-2, C-3) en microestacas de U. tomentosa

\begin{tabular}{|c|c|c|c|}
\hline Tratamiento & Antibiótico & $\begin{array}{c}\text { Concentración final del } \\
\text { medio de cultivo }\end{array}$ & $\begin{array}{c}\text { Porcentaje de } \\
\text { supervivencia de } \\
\text { explantes }(\mathbf{n}=30)\end{array}$ \\
\hline R-1 & Rifampicina & $40 \mathrm{mg} / \mathrm{L}$ & 80 \\
\hline R-2 & Rifampicina & $50 \mathrm{mg} / \mathrm{L}$ & 75 \\
\hline R-3 & Rifampicina & $60 \mathrm{mg} / \mathrm{L}$ & 20 \\
\hline C-1 & Cefotaxime & $200 \mathrm{mg} / \mathrm{L}$ & 73 \\
\hline C-2 & Cefotaxime & $250 \mathrm{mg} / \mathrm{L}$ & 66 \\
\hline C-3 & Cefotaxime & $300 \mathrm{mg} / \mathrm{L}$ & 22 \\
\hline
\end{tabular}


Establecimiento de ensayos de agroinfección de ápices pertenecientes a vitroplantas de U. tomentosa empleando las cepas ARI 500 y A4RS de A. rhizogenes

A partir de dos lotes de plántulas, se procedió a obtener ápices de I cm de longitud aproximadamente. Una vez obtenidos los explantes, se colocaron inmediatamente en medio MS (1962) líquido sin reguladores. Para la infección, los explantes se introdujeron en las soluciones bacterianas respectivas, con una DO600 final $=0.1$. Se dejaron remojando por 20 minutos. El exceso de líquido fue removido al colocar los explantes en un filtro Whatman \#3 estéril por unos segundos.

Luego se transfirieron a un medio MS (1962), ajustado a un $\mathrm{pH}$ de 5,7. Se colocaron tres explantes por frasco y se incubaron en oscuridad a $25-27^{\circ} \mathrm{C}$. Se subcultivaron los explantes infectados con las dos cepas cada tres días en medio de cultivo MS (1962), hasta el día 9 posterior a su infección con la solución de A. rhizogenes. Por último, se transfirieron a un medio de selección de transformantes, el cual consistía en un medio de cultivo MS (1962), así como los antibióticos Rifampicina $50 \mathrm{mg} / \mathrm{L}$ y Cefotaxime $250 \mathrm{mg} / \mathrm{L}$, y se incubaron a $25-27^{\circ} \mathrm{C}$ en oscuridad hasta que se observó el crecimiento de raíces pilosas.

De manera paralela, se realizaron ensayos de agroinfección en colaboración con la Universidad de California UC Davis. En esta institución se realizaron ensayos de agroinfección utilizando dos cepas de ATCC 15834, una que contenía el plásmido pCB5SGFP, facilitadas por el Dr. James Lincoln, investigador del Departamento de Plant Pathology de la Universidad de California, Davis.A estas cepas se les incorporó además el plásmido pCAMBIA I 38 IZ y los resultados fueron comprobados utilizando la expresión del gen de la proteína verde fluorescente (GFP) en microscopía confocal. Las vitroplantas de U. tomentosa utilizadas en el trabajo de investigación fueron proporcionadas por el CIB,TEC.

\section{Cultivo de raíces pilosas de $U$. tomentosa en medio líquido en agitación}

Se estableció un cultivo de raíces pilosas obtenidas mediante el protocolo de agroinfección y de igual manera se estableció un control a partir de raíces no transformadas de U. tomentosa. El medio de cultivo líquido utilizado fue un medio selectivo para transformantes que consistía en un MS (1962) con 50 mg/L de Kanamicina. Todos los cultivos se colocaron en un agitador orbital (shaker) a 90 rpm en oscuridad y a una temperatura de $25-27^{\circ} \mathrm{C}$ por tres semanas.

Luego de este periodo, los cultivos de raíces se subcultivaron en un medio MS (1962) líquido a la mitad de sus nutrientes y se cultivaron bajo las mismas condiciones de agitación, luminosidad y temperatura.

\section{Resultados y discusión}

Para realizar la infección de raíces de $U$. tomentosa productoras con metabolitos secundarios in vitro, fue necesario obtener material vegetal en adecuado estado fitosanitario y cepas de Agrobacterium viables. Para ello se probaron e implementaron protocolos y técnicas in vitro tanto de cultivo de tejidos vegetales como de cultivos bacterianos que se pudieran reproducir en un ambiente controlado, condiciones estériles y factores geográficos y climáticos independientes.

Luego de aplicar el correspondiente tratamiento para cultivo en invernadero, se obtuvieron rebrotes axilares en la mayoría de las plantas de U. tomentosa, los cuales presentaron las características ideales para un posterior establecimiento in vitro. En la figura I se muestra un planta de U. tomentosa con múltiples brotes cultivada en condiciones de invernadero en el CIB-TEC.

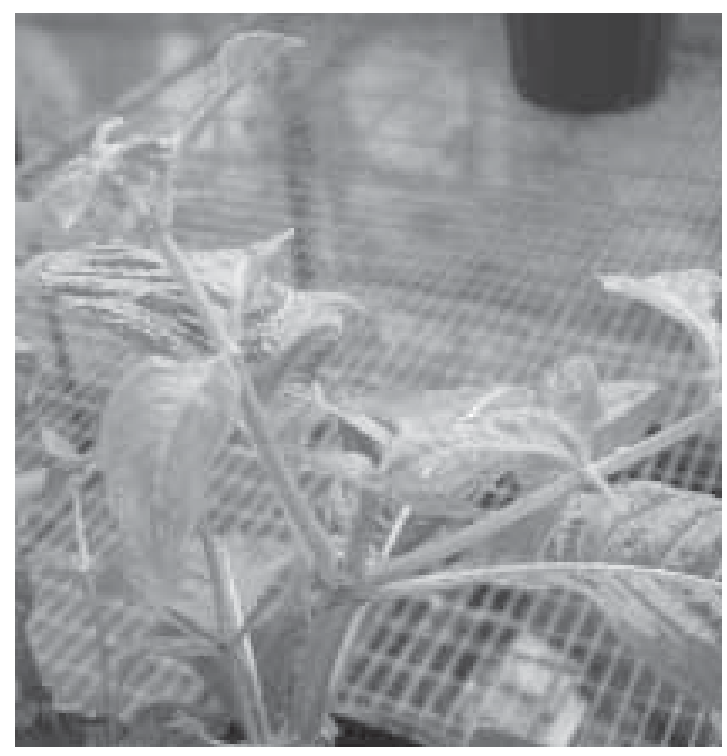

Figura I. Rebrotes axilares de una planta de $U$. tomentosa aclimatadas y cultivadas en el invernadero de investigación del CIB,TEC. 
Cuadro 2. Introducción a cultivo in vitro de microestacas de U. tomentosa

\begin{tabular}{|c|c|c|c|}
\hline Fecha & $\begin{array}{c}\text { Total de } \\
\text { vitroplantas }\end{array}$ & $\begin{array}{c}\text { \% contaminación por } \\
\text { hongos y bacterias }\end{array}$ & \% supervivencia total \\
\hline Semana I & 63 & 69.8 & 25.4 \\
\hline Semana 4 & 32 & 34.5 & 50.5 \\
\hline Total & 95 & 34.9 & 37.95 \\
\hline
\end{tabular}

Posteriormente, utilizando los rebrotes axilares de una planta de U. tomentosa, se obtuvieron microestacas para el establecimiento del cultivo in vitro respectivo. En el cuadro 2 se muestra un resumen de las introducciones de microestacas de $U$. tomentosa establecidas en un mes de cultivo.

A partir de las microestacas con un adecuado estado fitosanitario, se procedió a micropropagar, así como mantener el material vegetal in vitro de U. tomentosa. El material micropropagado permite mantener una fuente de insumos para la realización de los ensayos de infección, así como la conservación del mismo a corto y mediano plazo.

Muchos factores influyen en la probabilidad de obtener una transformación exitosa de tejido vegetal e inducción de raíces, incluyendo la especie, la edad, el tipo de tejido vegetal, el tipo de cepa de Agrobacterium y la densidad bacteriana en suspensión (Georgiev et al., 2007).

El protocolo de obtención de cultivos de cepas bacterianas viables se optimizó luego de varias modificaciones de la metodología descrita por Chistey y Braun (2005). Se considera que tanto el protocolo para establecer el cultivo bacteriano como la conservación de la viabilidad del mismo

Cuadro 3. Resultados de la densidad óptica a $600 \mathrm{~nm}$ de diferentes cultivos de A. rhizogenes

\begin{tabular}{|c|c|c|}
\hline Cepa & Repetición & $\mathrm{DO}_{600}$ \\
\hline \multirow{2}{*}{ A4PC } & $\mathrm{I}$ & $\mathrm{I}$ \\
\cline { 2 - 3 } & 2 & 1.065 \\
\hline \multirow{2}{*}{ ARI500 } & $\mathrm{I}$ & 0.893 \\
\cline { 2 - 3 } & 2 & 0.820 \\
\hline \multirow{2}{*}{ A4RS } & $\mathrm{I}$ & $\mathrm{I} .060$ \\
\cline { 2 - 3 } & 2 & 1.260 \\
\hline
\end{tabular}

resultan eficaces para la infección de explantes de uña de gato, debido a que se obtuvo un buen crecimiento bacteriano (turbidez) en todos los cultivos efectuados.

El crecimiento bacteriano de cada cepa se cuantificó por medio de la determinación de la densidad óptica a una longitud de onda de 600 nm $\left(\mathrm{DO}_{600}\right)$ a las cepas A4PC, ARI500 y A4RS. En el cuadro 3 se resumen los resultados de $\mathrm{DO}_{600}$ obtenidos para los cultivos bacterianos de las cepas A4PC, AR I 500 y A4RS, luego de haber empleado el protocolo optimizado de cultivo.

Se considera que los valores de $\mathrm{DO}_{600}$ obtenidos para las tres cepas son altos, ya que según la literatura (Peña, 2005, Wang, 2006), estos deben estar entre 0.5 y 0.8 , lo cual equivale aproximadamente a $10^{8}$ células por mililitro. De esta forma, se seleccionaron las cepas con concentraciones de entre 0.8 y I.I.

Asimismo, se requiere que los cultivos presenten una buena concentración bacteriana para que a la hora de ser almacenados mantengan su viabilidad. Con el empleo de la metodología descrita se almacenaron eficazmente muestras de las cepas A4RS, ARI 500 y A4PC sin que estas perdieran su viabilidad, lo cual se verificó en posteriores reconstituciones de las cepas en un medio de cultivo fresco.

Los ensayos de susceptibilidad de la planta a ambos antibióticos mostraron que esta es resistente a la Rifampicina y al Cefotaxime en concentraciones menores a los $60 \mathrm{mg} / \mathrm{l}$ y $300 \mathrm{mg} / \mathrm{L}$ respectivamente. De esta forma, los medios selectivos utilizados en la agroinfección fueron preparados con Rifampicina a 50 mg/L y Cefotaxime 250mg/L, lo cual fue concordante con lo recomendado en la literatura para ensayos similares de agroinfección en dicotiledóneas (Peña, 2005, Kumar et al., 2006).

El uso de Cefatoxime en los ensayos realizados previno el sobrecrecimiento de Agrobacterium, 
Cuadro 4. Evaluaciones semanales de los explantes de $U$. tomentosa sometidos al tratamiento de agroinfección con cepas silvestres de A. rhizogenes

\begin{tabular}{|c|c|c|c|c|c|c|c|c|c|}
\hline \multirow{2}{*}{ Semana } & \multicolumn{3}{|c|}{$\begin{array}{c}\text { Total de explantes por } \\
\text { tratamiento de infección }\end{array}$} & $\begin{array}{c}\text { \% contaminación por } \\
\text { hongos y bacterias }\end{array}$ & \multicolumn{3}{c|}{$\%$ supervivencia total } \\
\cline { 2 - 10 } & $\begin{array}{c}\text { Cepa } \\
\text { ARI500 }\end{array}$ & $\begin{array}{c}\text { Cepa } \\
\text { A4RS }\end{array}$ & Control & $\begin{array}{c}\text { Cepa } \\
\text { ARI500 }\end{array}$ & $\begin{array}{c}\text { Cepa } \\
\text { A4RS }\end{array}$ & Control & $\begin{array}{c}\text { Cepa } \\
\text { ARI500 }\end{array}$ & $\begin{array}{c}\text { Cepa } \\
\text { A4RS }\end{array}$ & Control \\
\hline Semana I & 30 & 30 & 30 & 0 & 0 & 0 & 100 & 100 & 100 \\
\hline Semana 2 & 30 & 30 & 30 & 2 & 0 & 0 & 87 & 100 & 100 \\
\hline Semana 4 & 26 & 30 & 30 & 7 & 0 & 0 & 63 & 100 & 100 \\
\hline TOTAL & 26 & 30 & 30 & 7 & 0 & 0 & 63 & 100 & 100 \\
\hline
\end{tabular}

disminuyendo la interferencia con la regeneración del explante. También se ha reportado que la combinación de Cefatoxime con sal potásica de ácido clavulánico es altamente conveniente para eliminar A. rhizogenes (Kumar et al., 2006). Otra forma mediante la cual se evitó el sobrecrecimiento de la bacteria durante los eventos de agroinfección, fue co-cultivando durante no más de tres días, pues el tiempo de co-cultivo usualmente es de dos a seis días. Mucho tiempo de incubación puede resultar en el excesivo desarrollo de las agrobacterias, lo que a la postre podría resultar en una sobreinfección de los explantes que sería nociva para los tejidos.

Posteriormente se realizó un primer ensayo de agroinfección utilizando ápices de $U$. tomenosa y las cepas A4RS, ARI 500 y A4PC. A estos explantes se les hicieron pequeñas heridas en los tejidos, ya que se ha demostrado que el daño mecánico a los tejidos tiene una función vital para la infección eficaz de los mismos (Wang, 2006).

La herida hecha al tejido vegetal puede tener tres funciones: promover el acceso de la bacteria a los sitios de reconocimiento sobre la superficie celular, promover la división celular -lo cual hace a las células vegetales competentes para la transformación-, y estimular la producción de compuestos fenólicos (acetosiringona, $\alpha$ - hidroxiacetosiringona, ácido sinapínico y ácido cafeico) asociados a la herida, los cuales son los responsables de la atracción por quimiotaxis de Agrobacterium, induciendo la expresión de genes vir requeridos para transferir el ADN-T (Rodríguez, 2002).

Las microestacas infectadas con las cepas A4RS y ARI500 presentaron crecimiento de raíces adventicias. Por otro lado, cuando se experimentó con la cepa A4PC en las mismas condiciones, las microestacas infectadas con esta no mostraron crecimiento radicular luego de un mes y presentaron etiolación durante el co-cultivo con A. rhizogenes. Debido a esto se descartó el uso de esta cepa para posteriores ensayos de agroinfección. En el cuadro 4 se presentan los resultados de la agroinfección.

A las cuatro semanas del co-cultivo de los explantes con las cepas A4RS y ARI500 (agroinfección), se obtuvieron raíces pilosas en el $80 \%$ de los ensayos con la cepa ARI500 y un 65\% (cuadro 5) en los ensayos realizados con la cepa A4RS (figura 2). Posteriormente a la emersión de las raíces, estas se mantuvieron en cultivo semisólido por una semana

Cuadro 5. Porcentaje de explantes de U. tomentosa que presentan raíces pilosas (hairy roots) cuatro semanas después del tratamiento de agroinfeción con las cepas A4RS y ARI500 de A. rhizogenes

\begin{tabular}{|c|c|c|c|c|c|}
\hline \multicolumn{2}{|c|}{$\begin{array}{c}\text { Total de explantes por tratamiento de } \\
\text { agroinfección a las cuatro semanas }\end{array}$} & \multicolumn{3}{c|}{$\begin{array}{c}\text { Porcentaje de explantes que presentan raíces } \\
\text { pilosas (hairy roots) }\end{array}$} \\
\hline $\begin{array}{c}\text { Cepa } \\
\text { ARI500 }\end{array}$ & Cepa A4RS & Control & Cepa ARI500 & Cepa A4RS & Control \\
\hline 26 & 30 & 30 & 85 & 65 & 0 \\
\hline
\end{tabular}




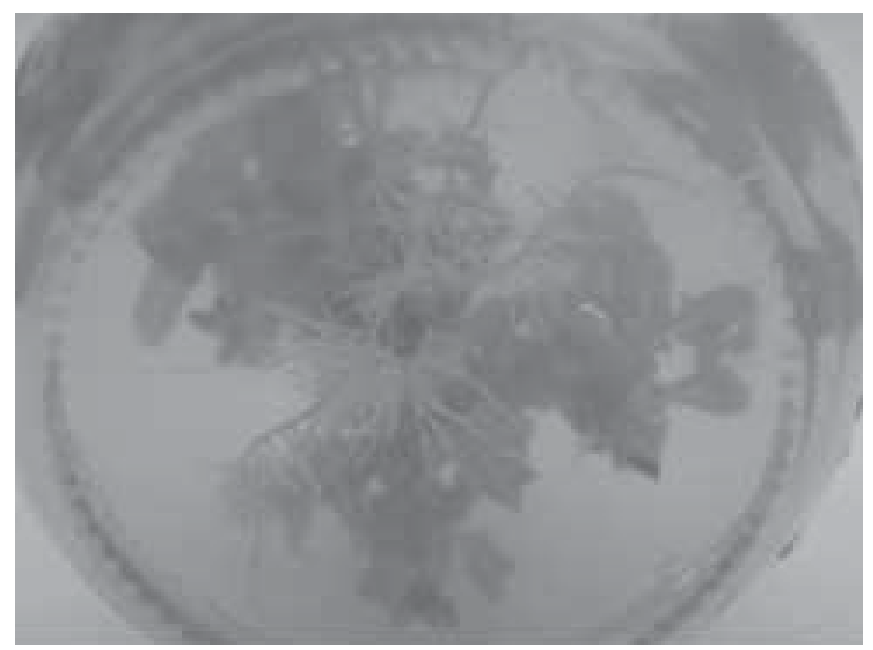

Figura 2. Raíz de explantes de U. tomentosa, con morfología pilosa generada a las tres semanas de infección por la cepa A4RS de A. rhizogenes.

más, con el fin de promover su alargamiento y madurez.

Se tomaron segmentos de las raíces pilosas establecidas en el cultivo semisólido de aproximadamente $2 \mathrm{~cm}$ de largo, mostrando la morfología típica (pilosa) deseable (figura 5). Estos segmentos fueron introducidos a cultivo líquido en agitación utilizando un medio líquido MS (1962) conteniendo la mitad de los nutrientes (MS 50\%) y sin reguladores. Para este ensayo se estableció un control a partir de raíces no agroinfectadas de $U$. tomentosa.

En el cuadro 6 se presenta la evaluación de la supervivencia de estas raíces agroinfectadas por un periodo de cuatro semanas en medio líquido en agitación constante y a la luz.
Se obtuvieron resultados adicionales en colaboración con colegas de la UC Davis, siguiendo la metodología utilizada en el presente estudio pero variando el tipo de cepa de A. rhizogenes por una cepa modificada (ATCCI5834) con la incorporación del plásmido pCB5SGFP. Por medio de tinciones histoquímicas y la detección de la proteína verde fluorescente (GFP) en raíces de tomate infectadas con las cepas ATCC 15834, se determinó el éxito de la agroinfección utilizando microscopía confocal láser (figura 3, A y B).

\section{Conclusiones}

Los medios LB y YEB resultaron adecuados para el cultivo de las cepas bacterianas de A. rhizogenes. A partir de la metodología implementada se logró un inóculo adecuado para el proceso y evaluar

Cuadro 6. Evaluación semanal de las raíces pilosas de U. tomentosa en medio líquido generadas en el proceso de agropinfección con las cepas ARI500 y A4RS de A. rhizogenes

\begin{tabular}{|c|c|c|c|c|c|c|c|c|c|}
\hline \multirow{2}{*}{ Fecha } & \multicolumn{3}{|c|}{ Erlenmeyers inoculados } & \multicolumn{2}{c|}{ Erlenmeyers contaminados } & \multicolumn{3}{c|}{$\%$ de supervivencia } \\
\cline { 2 - 10 } & $\begin{array}{c}\text { Cepa } \\
\text { ARI500 }\end{array}$ & $\begin{array}{c}\text { Cepa } \\
\text { A4RS }\end{array}$ & Control & $\begin{array}{c}\text { Cepa } \\
\text { ARI500 }\end{array}$ & $\begin{array}{c}\text { Cepa } \\
\text { A4RS }\end{array}$ & Control & $\begin{array}{c}\text { Cepa } \\
\text { ARI500 }\end{array}$ & $\begin{array}{c}\text { Cepa } \\
\text { A4RS }\end{array}$ & Control \\
\hline $08 / 08 / 07$ & 7 & 7 & 2 & 0 & 0 & 0 & 100 & 100 & 100 \\
\hline $15 / 08 / 07$ & 7 & 7 & 2 & 0 & 0 & 0 & 100 & 100 & 100 \\
\hline $22 / 08 / 07$ & 7 & 7 & 1 & 0 & 0 & 1 & 100 & 100 & 50 \\
\hline Total & 7 & 7 & 1 & 0 & 0 & 1 & 100 & 100 & 50 \\
\hline
\end{tabular}



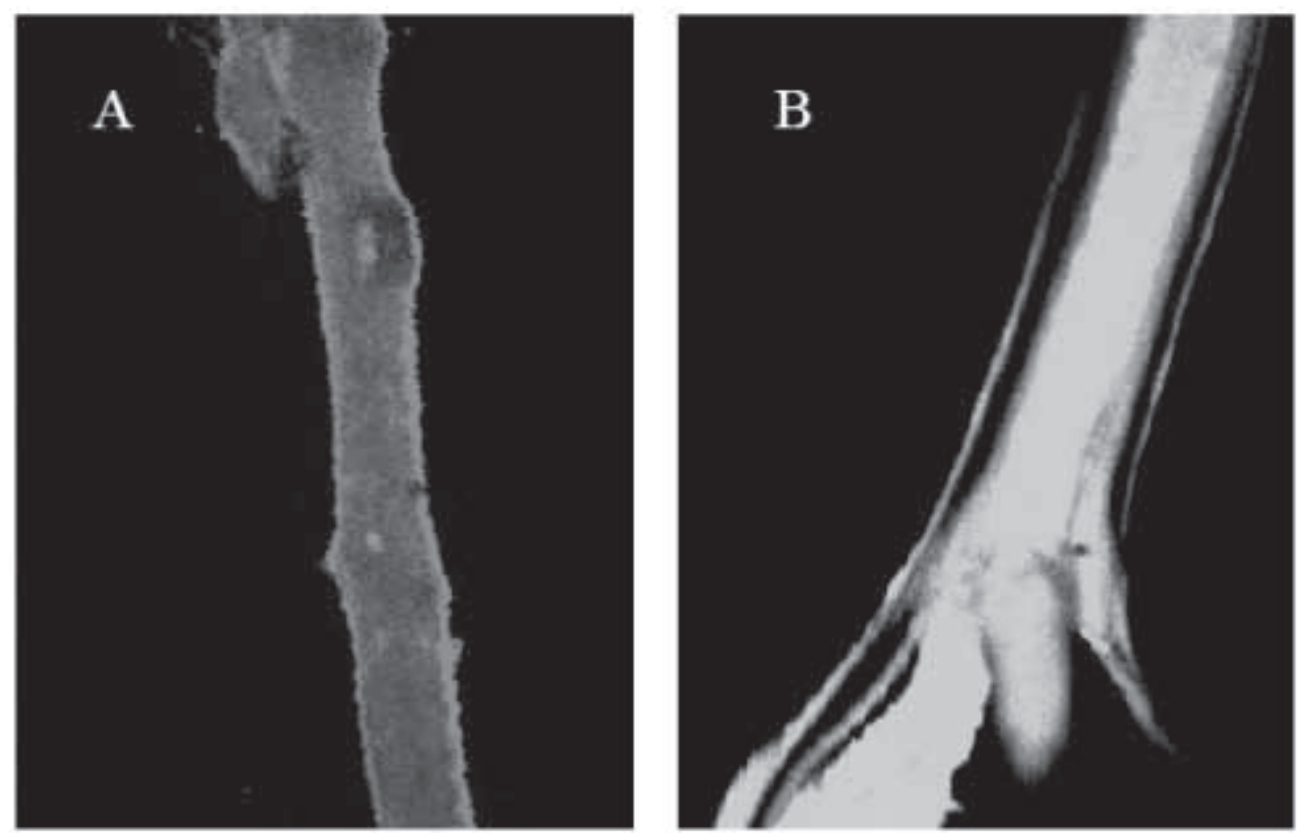

Figura 3. Detección de GFP con microscopio confocal láser. A: raíz de U. tomentosa control negativo sin gen reportero, B: raíz de U. tomentosa transformada con la cepa ATCC I5834 PCB5SGFP. Aumento $100 \mathrm{X}$.

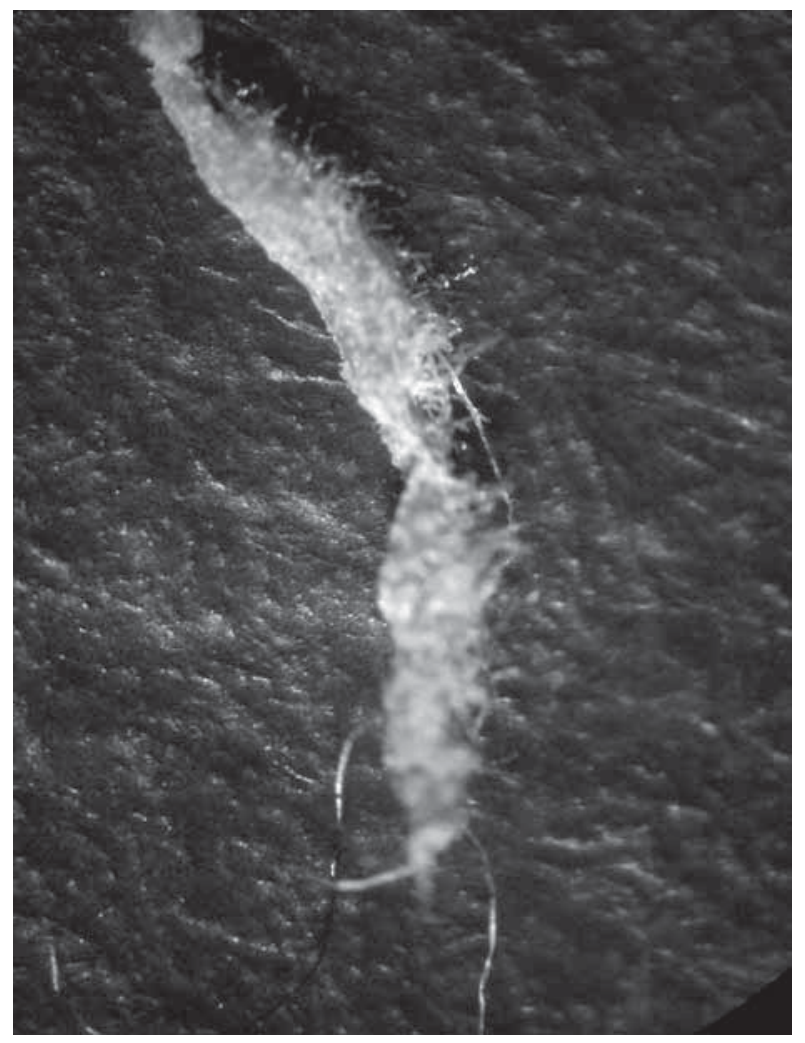

Figura 4. Raíz pilosa de U. tomentosa mostrando la morfología típica de "hairy root" generada a partir de la infección con la cepa silvestre ARI500 en explantes de esta especie observados en estereoscopio (Aumento 80X). densidades óptimas de $\left(\mathrm{DO}_{600}\right)$ de entre 0.8 y l.I, las cuales en ambos casos resultaron apropiadas para los ensayos de agroinfección realizados.

Las cepas A4RS y ARI 500 son eficaces en la inducción del crecimiento de raíces pilosas en vitroplantas infectadas de uña de gato ( $U$. tomentosa). Aunado a esto, se deben reconstituir inicialmente estas cepas en un medio básico para mantener su viabilidad.

Las microestacas son el tejido más adecuado para la agroinfección, debido a su anatomía y su relativa resistencia a la necrosis y el marchitamiento. Se debe tener en consideración la edad del cultivo del material biológico empleado, pues esto incide directamente en las frecuencias de infección.

En cuanto a los antibióticos de selección utilizados, la concentración de Cefatoxime (250 mg/L) es apta para la eliminación de la bacteria y no representa una fuente de intoxicación para la planta. La kanamicina es eficaz en la selección de los cultivos transformados (50 mg/L); sin embargo, resulta fotolábil, por lo cual se debe mantener el cultivo en oscuridad antes de cultivar por un periodo de 16 horas luz.

A partir de los resultados generados en colaboración con la UC (Davis), se pudo comprobar que la metodología utilizada en este trabajo fue exitosa y la incorporación de genes reporteros como el GFP 


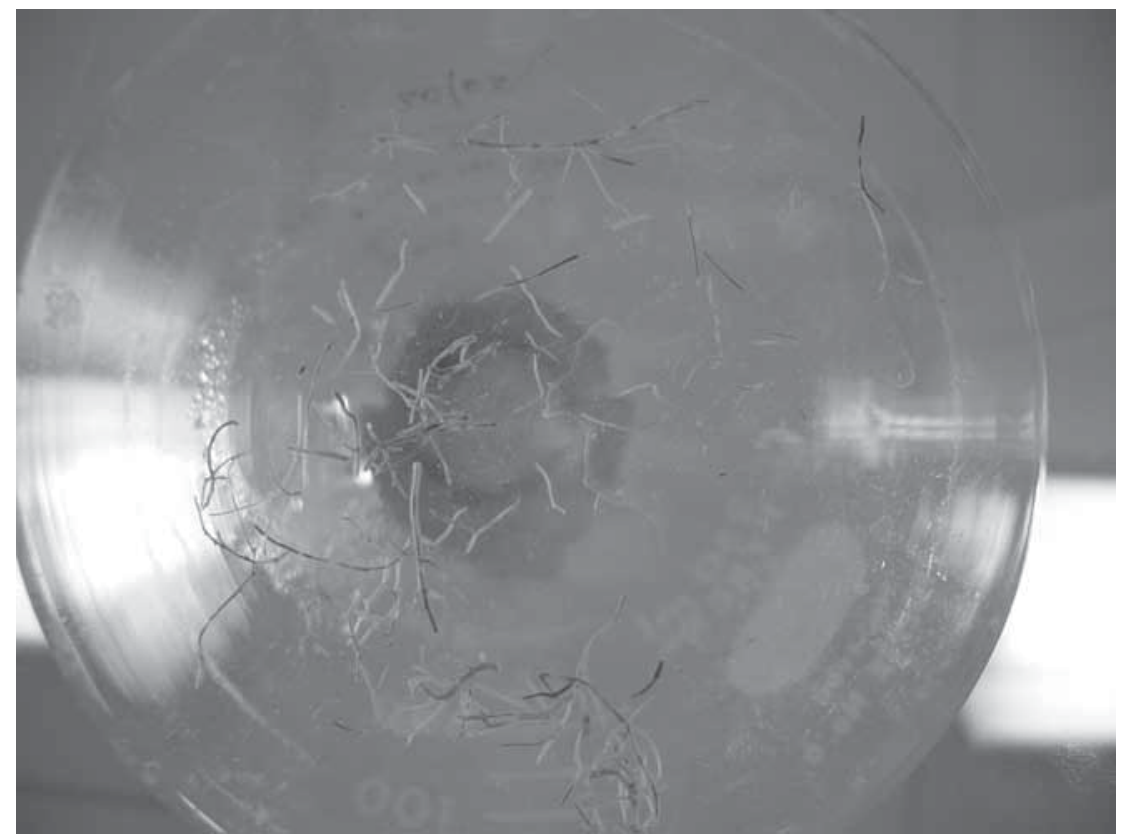

Figura 5. Cultivo de raíces agroinfectadas de U. tomentosa con morfología pilosa (hairy root) en crecimiento en medio líquido MS (1962) a una concentración del 50\% y en condiciones de oscuridad.

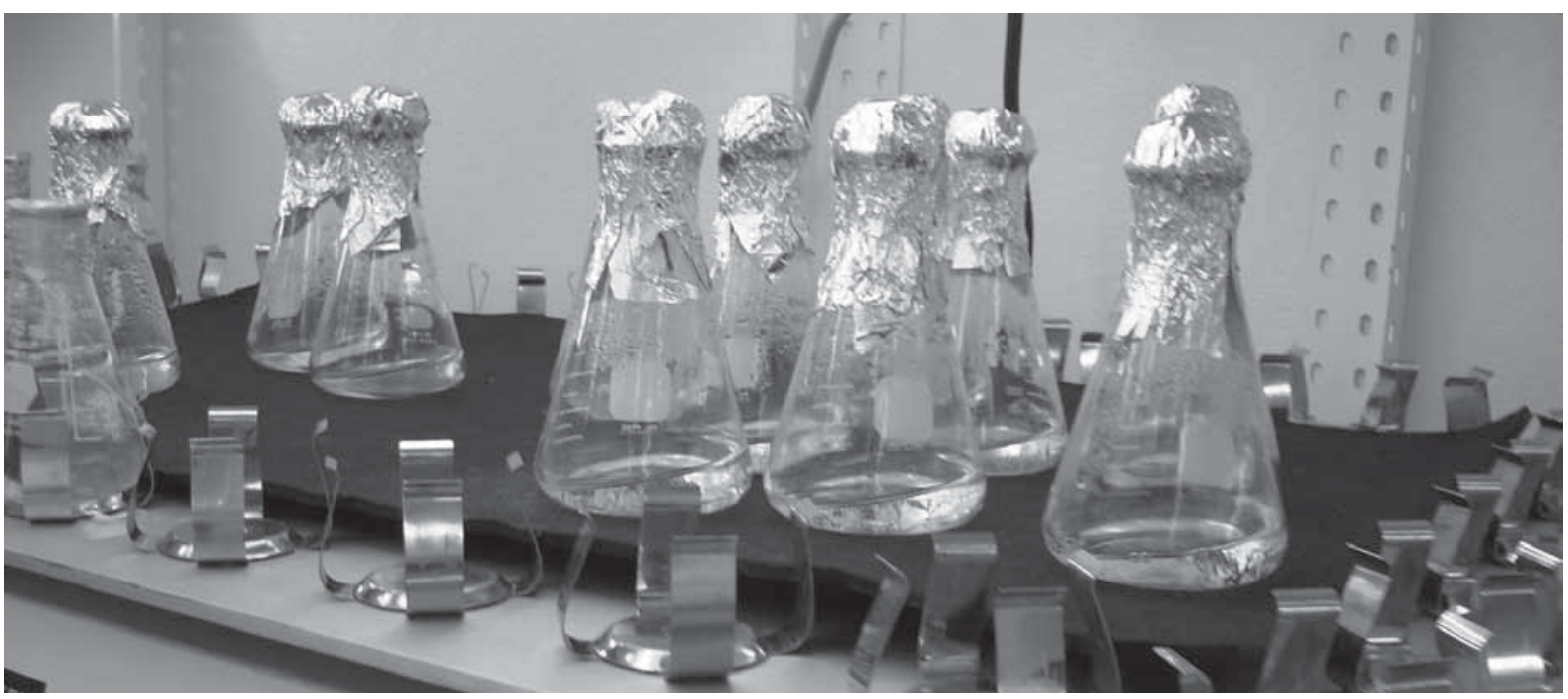

Figura 6. Cultivos de raíces agroinfectadas de U. tomentosa con morfología pilosa (hairy root) en crecimiento en medio líquido MS (1962) a una concentración del 50\% en el agitador orbital.

resulta una herramienta eficaz en la confirmación de los eventos de transformación genética de plantas por las cepas de A. rhizogenes. Sin embargo, esta práctica se ve limitada por el acceso a los recursos moleculares (genes, vectores) y la vigilancia requerida para este tipo de eventos de transformación genética por parte de las autoridades nacionales competentes.

Para futuros ensayos se recomienda la implementación adicional de técnicas moleculares (PCR) para la confirmación de la presencia de los genes rol de A. rhizogenes en el genoma de los cultivos de raíces generados. 


\section{Bibliografía}

Alvarenga, S.; Arnáez, E.; Moreira, I.; Alan, E.; Peraza, J.; Romero, E.; Vargas, W.; Loaiza, J. \& Barrios, M. (2008). Domesticación de Uncaria tomentosa (uña de gato) en Costa Rica. En: Oliver, R., Tabaoda, M. \& Granejo, A.E. (compiladores). Manejo Integrado de Recursos Bióticos. Estudios de Casos. México D.F: AGT Editor, S.A. p. $135-146$.

Alvarenga, S. (2010). Establecimiento in vitro y cultivo de células de la uña de gato (Uncaria tomentosa) (Willd.) D.C. Tecnología en Marcha 23(5): 24-33.

Bobrowski, P.). (2004). Methods and preparations of extracts of Uncaria species with reduced alkaloid content. United States Patent No.: U.S 2004/0068I 30 AI. Apr. 8.

Falkiewicz, B. \& Uukasiak, J. (200I). A review of published scientific literature of Vilcacora [Uncaria (Willd.) DC. and Uncaria guianensis (Aublet) Gmell. Case Reports and Clinical 2(4): 305-3। 6.

Georgiev, M.; Pavlov, A. \& Bley, T. (2007). Hairy root type plant in vitro systems as sources of bioactive substances. Applied Microbiology and Biotechnology 74(6).

Heitzman, M.; Neto, C.; Winiarz, E.; Vaisberg,A.\& Hammond, G.B. (2005). Review Ethnobotany, phytochemistry and pharmacology of Uncaria (Rubiaceae). Phytochemistry 66: 5-29.

Keplinger, K.; Laus, G.; Wurm, M.; Dierich, M. \& Teppner, H. (1998). Uncaria tomentosa (Willd.) DC.-- ethnomedicinal use and new pharmacological, toxicological and botanical results. Journal Ethnopharmacol 64(I):23-34.

Kumar, V.; Satyanarayana, K.; Itty, S.; Indu, E.; Giridhar, P.; Chandrashekar, A. \& Ravishankar, G. (2006). Stable transformation and direct regeneration in Coffea canephora $P$ ex. Fr. by Agrobacterium rhizogenes mediated transformation without hairy-root phenotype. Plant cell Rep 25: 214-222.

Murashige, T. \& Skoog, G. (1962). A revised medium for rapid growth and bioassays with tobacco tissue cultures. Physiol. Plant 15:473-497.

Náder, B.; Cardoso, A.; Iturriga, G.; Pereda, R. \& Villarreal, M. (2004). Genetic transformation of Galphimia glauca by Agrobacterium rhizogenes and the Production of Norfriedelanes. Planta Med 70: | |74- | | 79.

Peña, L. (2005). Transgenic Plants. Methods and Protocols. Instituto de Investigaciones Agrarias. Valencia, España: Humana Press, $437 \mathrm{p}$.

Pereira, R.; Valente, L.; Pinto, J.; Bertolucci, S.; Bezerra, G.; Alves, F.; dos Santos, P.; Benevides, P.; Siani, A.; Rosario, S.; Mazzei, J.; d'Avila, L.; Gomes, L.; AquinoNeto, F.; Emmerick, l. \& Carvalhaes, S. (2008). In vitro cultivated Uncaria tomentosa and Uncaria guianensis with determination of the pentacyclic oxindole alkaloid contents and profiles. Journal. Braz. Chem. Soc. 19(6): | | $93-1200$.

Pero, R.W. (200I). Method of preparation and composition of a water soluble extract of the plant species Uncaria for enhancing immune, anti-iflammatory, anti-tumor and DNA repair processes of warm blooded animal. United States Patent No.: U.S 2001/002298I AI. Sep. 20.

Rodríguez, H. (2002). Inducción del enraizamiento en Agave salmiana Otto con Agrobacterium rhizogenes y colonización de raíces transformadas por Glomus intraradices. Tesis de Doctorado. Universidad de Colima, Tecomán, México. I 4 p.

Wang, K. (2006). Agrobacterium protocols. Methods in Molecular Biology 343. 2ed. Volume I. New Jersey: Human Press. 